\title{
STATUS PERIKANAN HUHATE (POLE AND LINE) DI BITUNG, SULAWESI UTARA
}

\author{
Budi Nugraha1) dan Enjah Rahmat ${ }^{2)}$ \\ 1) Peneliti pada Balai Riset Perikanan Laut, Muara Baru-Jakarta \\ 2) Teknisi Litkayasa pada Balai Riset Perikanan Laut, Muara Baru-Jakarta
}

Teregristrasi I tanggal: 4 April 2008; Diterima setelah perbaikan tanggal: 30 April 2008; Disetujui terbit tanggal: 14 Mei 2008

\begin{abstract}
ABSTRAK
Tulisan ini menyajikan tentang status perikanan huhate di Bitung meliputi deskripsi unit penangkapan, daerah penangkapan, komposisi hasil tangkapan, catch per unit of effort, dan ukuran ikan pertama kali tertangkap. Data dikumpulkan selama tahun 2004 sampai dengan 2005. Hasil penelitian menunjukkan bahwa huhate yang terdapat di Bitung dioperasikan dengan kapal penangkapan yang terbuat dari kayu berukuran 50 sampai dengan 80 GT. Daerah penangkapan di sekitar lokasi rumpon di Laut Sulawesi dan Laut Maluku. Hasil tangkapan yang diperoleh terdiri atas cakalang (Katsuwonus pelamis), madidihang (Thunnus albacares), baby tuna (Thunnus spp.), dan tongkol (Auxis spp.) serta hasil tangkapan sampingan yaitu lemadang (Coryphaena hippurus) dan sunglir (Elagatis bipinnulatus). Hasil analisis catch per unit of effort diperoleh bahwa nilai catch per unit of effort baby tuna (Thunnus spp.) mengalami kenaikan pada bulan Agustus 2004, dan cakalang (Katsuwonus pelamis) mengalami kenaikan pada bulan September 2004. Hasil analisis terhadap ukuran pertama kali cakalang (Katsuwonus pelamis) tertangkap oleh huhate 49,3 FLcm. Ukuran ini lebih panjang dibandingkan ukuran pertama kali cakalang (Katsuwonus pelamis) matang gonad. Sedangkan hasil analisis terhadap ukuran pertama kali madidihang (Thunnus albacares) tertangkap oleh huhate 51,6 FLcm. Ukuran ini lebih pendek dibandingkan ukuran pertama kali madidihang (Thunnus albacares) matang gonad.
\end{abstract}

KATAKUNCl: huhate, catch per unit of effort, ukuran pertama kali tertangkap, cakalang, madidihang, Bitung

\section{ABSTRACT: Status of Pole and Line Fishery in Bitung, North Sulawesi. By: Budi Nugraha and Enjah Rahmat}

This paper presents the status of pole and line fishery in Bitung of North Sulawesi, consisting of description of fishing gear, fishing ground, catch composition, catch per unit of effort, and length at first capture. Data were collected during the period of 2004 until 2005. Results show that the pole and line in Bitung operated by wooden vessels of 50 until 80 GT. The fishing grounds were the waters around FADs location in Sulawesi Sea and Maluku Sea. Catch composition consists of skipjack tuna (Katsuwonus pelamis), yellow fin tuna (Thunnus albacares), baby tuna (Thunnus spp.), and frigate tuna (Auxis spp.), while the bycatch consisted of dolphinfish (Coryphaena hippurus) and rainbow runner (Elagatis bipinnulatus). Catch per unit of effort analysis shows that catch per unit of effort value of baby tuna (Thunnus spp.) increased on August 2004, whereas catch per unit of effort value of skipjack tuna (Katsuwonus pelamis) increased on September 2004. The length at first capture of skipjack tuna (Katsuwonus pelamis) was 49,3 FLcm. The catch size was bigger than the length at first maturity for skipjack tuna (Katsuwonus pelamis). The length at first capture of yellowfin tuna (Thunnus albacares) was 51,6 FLcm. This catch size was smaller than the length at first maturity for yellowfin tuna (Thunnus albacares).

\section{KEYWORDS: $\quad$ pole and line, catch per unit of effort, length at first captured, skipjack, yellow fin} tuna, Bitung,

\section{PENDAHULUAN}

Huhate (pole and line) adalah alat tangkap yang terdiri atas joran atau bambu, tali pancing dan mata pancing. Alat tangkap ini khusus dipakai untuk menangkap cakalang (Katsuwonus pelamis). Alat ini sering disebut pancing cakalang (Diniah et al., 2001). Alat tangkap ini cukup berkembang di kawasan timur Indonesia terutama di Bitung pada tahun 1970-an, sejak didirikan perusahaan milik negara yaitu PT. Perikani.
Sejak dikembangkan joint venture penangkapan tuna (Thunnus) dan cakalang (Katsuwonus pelamis) di perairan Laut Sulawesi dan di sekitar dengan menggunakan pukat cincin (purse seine) pada akhir tahun 1990 antara Indonesia dan Philipina, perikanan huhate dan mini huhate (funai) kurang berkembang. Pukat cincin yang beroperasi dari Philipina menggunakan rumpon laut dalam yang tersebar di seluruh perairan Laut Sulawesi dan di sekitar seperti memagari perairan tersebut. Kapal-kapal huhate yang memiliki gross tonase kurang dari 30 GT dan kapal- 
kapal funai banyak yang tidak beroperasi karena sulit menangkap ikan tuna (Thunnus) dan cakalang (Katsuwonus pelamis). Hal ini, dikarenakan dampak dari pemasangan rumpon yang dilakukan oleh Philipina di mana ikan-ikan tuna (Thunnus) dan cakalang (Katsuwonus pelamis) yang dahulu banyak berada di sekitar perairan pantai, sekarang sudah jarang karena tertahan oleh rumpon-rumpon tersebut. Untuk menyiasati hal tersebut, nelayan-nelayan huhate mulai membangun kapal-kapal yang berukuran besar sampai dengan 60 GT bahkan lebih sehingga dapat beroperasi di luar rumpon sampai dengan ke perairan Laut Maluku, Teluk Tomini, dan di sekitar.

Sampai dengan saat ini perikanan huhate di Bitung tetap bertahan dengan ukuran kapal rata-rata 50 sampai dengan 80 GT. Berdasarkan pada data statistik perikanan tangkap Propinsi Sulawesi Utara (2004), alat tangkap huhate di Bitung pada tahun 2003 meningkat tajam dibandingkan dengan tahun 2002 di mana pada tahun 2003 jumlah mencapai 159 unit, sedangkan pada tahun 2002 hanya berjumlah 58 unit. Peningkatan jumlah ini dapat diasumsikan bahwa perikanan huhate di Bitung mulai berkembang lagi. Tulisan ini menyajikan tentang status perikanan huhate di Bitung meliputi deskripsi unit penangkapan, daerah penangkapan, komposisi hasil tangkapan, catch per unit of effort dan ukuran ikan pertama kali tertangkap.

\section{BAHAN DAN METODE}

\section{Pengumpulan Data}

Pengumpulan data dilakukan di Pelabuhan Perikanan Bitung selama tahun 2004 sampai dengan 2005. Jenis data yang dikumpulkan adalah data operasional penangkapan yaitu deskripsi alat tangkap, daerah penangkapan, dan komposisi hasil tangkapan serta data biologi yaitu frekuensi ukuran panjang.

Data operasional penangkapan diperoleh dengan cara wawancara dan mengikuti kegiatan penangkapan kapal huhate yang berbasis di Bitung. Data biologi diperoleh dari hasil pengukuran yang dilakukan enumerator di lapangan.

\section{Analisis Data}

Untuk mengetahui hasil tangkapan per satuan upaya (catch per unit of effort) menggunakan rumus Sparre \& Venema (1999), yaitu:

$$
\text { CPUE }=\underline{\text { Catch }}
$$

di mana:

CPUE : catch per unit effort (tangkapan per satuan upaya)

Catch : Jumlah hasil tangkapan ( $\mathrm{g}, \mathrm{kg}$, dan ton)

Effort : Jumlah upaya (hari, trip, dan unit)

Pendugaan ukuran ikan pertama kali tertangkap menggunakan persamaan Kerstan (1985), yaitu:

$$
Y(\%)=\left[100 /\left(1+a * e^{\wedge}-b * x\right)\right] \ldots \ldots \ldots \ldots(2
$$

di mana:

$\mathrm{Y}(\%)$ : proporsi tertahan pada setiap titik kelas panjang

a : koefisien intersepsi

b : slope

e : eksponensial

x : ukuran pertama kali tertangkap $(L C)$

\section{HASIL DAN BAHASAN}

\section{Deskripsi Unit Penangkapan}

Huhate adalah salah satu alat tangkap yang digunakan khusus untuk menangkap cakalang. Ada beberapa keistimewaan dalam penangkapan cakalang (Katsuwonus pelamis) dengan huhate, yaitu pertama ada umpan hidup (live baits) dan ke-2 adalah ada bentuk kapal yang khusus (Subani \& Barus, 1988). Huhate dioperasikan sepanjang siang hari pada saat terdapat gerombolan ikan di sekitar kapal. Alat tangkap ini bersifat aktif di mana kapal akan mengejar gerombolan ikan. Setelah gerombolan ikan berada di sekitar kapal, lalu diadakan pemancingan.

Pengoperasian huhate pada prinsip adalah mengumpulkan ikan yang dirangsang dengan lemparan umpan hidup dan semprotan air. Operasi penangkapan dilakukan pada siang hari di sekitar rumpon dengan memperhatikan lingkungan di sekitar seperti ada burung di atas permukaan air laut. Kondisi ini merupakan indikasi ada gerombolan ikan yang menjadi sasaran penangkapan.

Joran bambu yang digunakan berukuran panjang $2,5 \mathrm{~cm}$, pada bagian pangkal mempunyai diameter sekitar $5 \mathrm{~cm}$ dan meruncing ke arah ujung. Pangkal joran diberi gulungan karet agar tidak licin. Tali utama pancing huhate terbuat dari PE dengan diameter 3 $\mathrm{mm}$ dan panjang $1,5 \mathrm{~m}$. Tali cabang terbuat dari nilon monofilamen No.1.000 yang mempunyai panjang 30 $\mathrm{cm}$. Tali (utama dan cabang) pada umumnya $40 \mathrm{~cm}$ lebih pendek dari joran. Hal ini, untuk memudahkan nelayan mengayun ikan di atas kepala dan 
melepaskan ikan tangkapan dengan cara mengendorkan tali.

Terdapat beberapa keunikan dari alat tangkap huhate, salah satu adalah bentuk mata pancing yang tidak berkait seperti lazim mata pancing. Mata pancing huhate ditutupi bulu-bulu ayam atau potongan rafia yang halus agar tidak tampak oleh ikan. Pancing huhate dibuat tidak berkait balik yang bertujuan agar ikan yang tertangkap lebih mudah dilepaskan. Mata pancing berukuran kecil digunakan untuk ikan dengan ukuran relatif kecil $(<1 \mathrm{~kg})$, sedang mata pancing berukuran besar digunakan untuk ikan dengan ukuran $(>1,5 \mathrm{~kg})$.

Kapal huhate pada umumnya adalah kapal kayu yang mempunyai tonase berkisar 50 sampai dengan 80 GT dengan tenaga penggerak berkisar 350 sampai dengan $450 \mathrm{PK}$, dilengkapai pula mesin bantu untuk penerangan dan suplai air masing-masing 90 sampai dengan 155 PK. Pada dek kapal terdapat palkah sekitar 7 sampai dengan 8 buah dengan volume masing-masing berbeda-beda berkisar 2 sampai dengan 4 ton. Dua buah palkah di bagian tengah digunakan untuk menyimpan umpan hidup, yang lain digunakan untuk menyimpan ikan, es balok, dan air tawar. Bagian haluan kapal huhate mempunyai konstruksi khusus, dimodifikasi menjadi lebih panjang, sehingga dapat dijadikan tempat duduk oleh pemancing. Kapal dilengkapi pula dengan alat penyemprot air (water sprayer) terdiri atas sebatang pipa baja, dipasang memanjang di atas platform (Gambar 1a).

Anak buah kapal kapal huhate berkisar 30 sampai dengan 40 orang, terdiri atas nakhoda (kapten), wakil nakhoda, fishing master, juru umpan, KKM, pemancing, pengawet (juru ikan), koki, dan juru mudi. Pemancingan dilakukan serempak oleh seluruh anak buah kapal, kecuali nakhoda, juru umpan, juru ikan, dan juru mudi. Pemancing duduk di sekeliling kapal dengan pembagian kelompok berdasarkan pada keterampilan memancing. Pemancing I adalah pemancing paling unggul dan diberi posisi di bagian haluan kapal, dimaksudkan agar lebih banyak ikan tertangkap. Pemancing II diberi posisi di bagian lambung kiri dan kanan kapal. Sedangkan pemancing III berposisi di bagian buritan, pada umumnya adalah orang-orang yang baru belajar memancing dan pemancing berusia tua yang tenaga sudah mulai berkurang atau sudah lamban. Hal itu, yang perlu diperhatikan adalah pada saat pemancingan dilakukan jangan ada ikan yang lolos atau jatuh kembali ke perairan, karena hal ini dapat menyebabkan gerombolan ikan menjauh dari lokasi sekitar kapal (Gambar 1b).
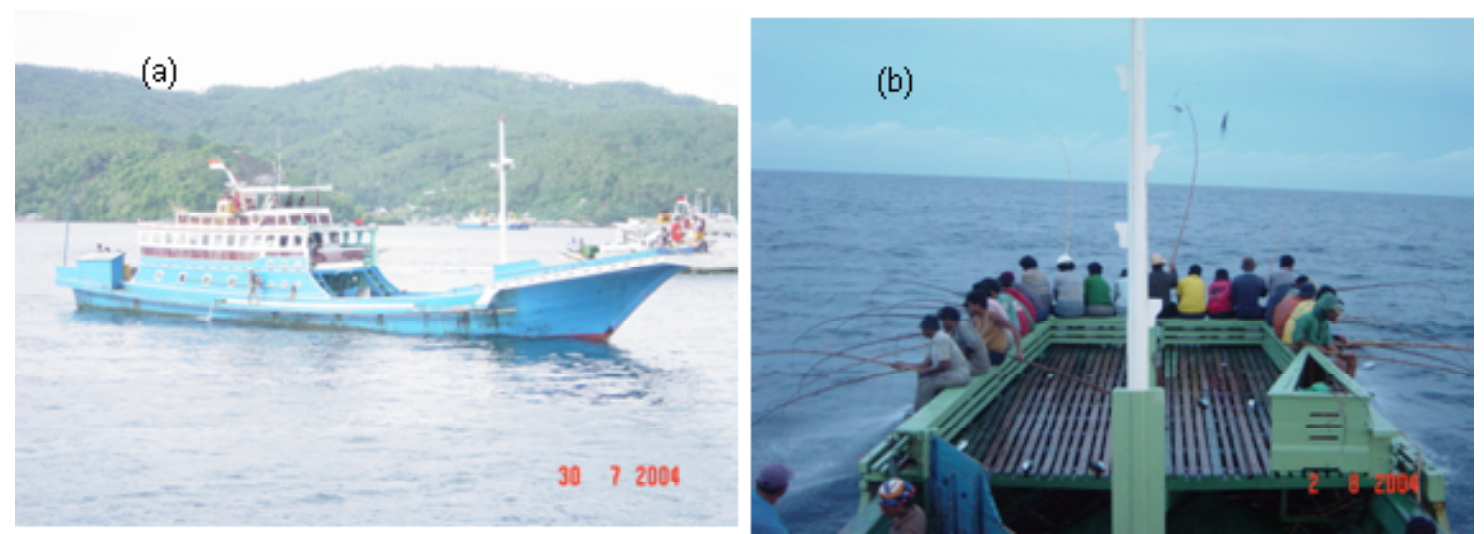

Gambar 1. Kapal huhate (a) dan operasi penangkapan dengan menggunakan huhate (b). Figure 1. Pole and line vessel (a) and fishing operation using pole and line (b).

Umpan yang digunakan adalah umpan hidup, dimaksudkan agar setelah ikan umpan dilempar ke perairan akan berusaha kembali naik ke permukaan air. Hal ini, akan mengundang cakalang (Katsuwonus pelamis) untuk mengikuti naik ke dekat permukaan. Selanjutnya dilakukan penyemprotan air melalui sprayer. Penyemprotan air dimaksudkan untuk mengaburkan pandangan ikan, sehingga tidak dapat membedakan antara ikan umpan sebagai makanan atau mata pancing yang sedang dioperasikan. Umpan hidup yang digunakan adalah teri (Stolephorus spp.).

\section{Daerah Penangkapan}

Penangkapan ikan dilakukan sepanjang tahun, baik musim barat, peralihan, maupun musim timur. Daerah penangkapan nelayan-nelayan huhate berupa rumpon yang berada di Laut Sulawesi dan Laut Maluku. Dalam melakukan operasi penangkapan, kapal-kapal huhate Bitung menggunakan beberapa peralatan elektronik seperti global positioning system dan echosounder, terutama untuk kapal yang berukuran $80 \mathrm{GT}$. Penggunaan peralatan tersebut 
dimaksudkan untuk mempermudah dalam pencarian lokasi penangkapan (rumpon). Kapal-kapal yang memiliki global positioning system sudah menyimpan data posisi-posisi rumpon yang ada di perairan Laut
Sulawesi dan Laut Maluku. Jenis rumpon yang digunakan adalah rumpon laut dalam. Daerah penangkapan (rumpon-rumpon) kapal-kapal huhate yang berbasis di Bitung dapat dilihat pada Gambar 2 .

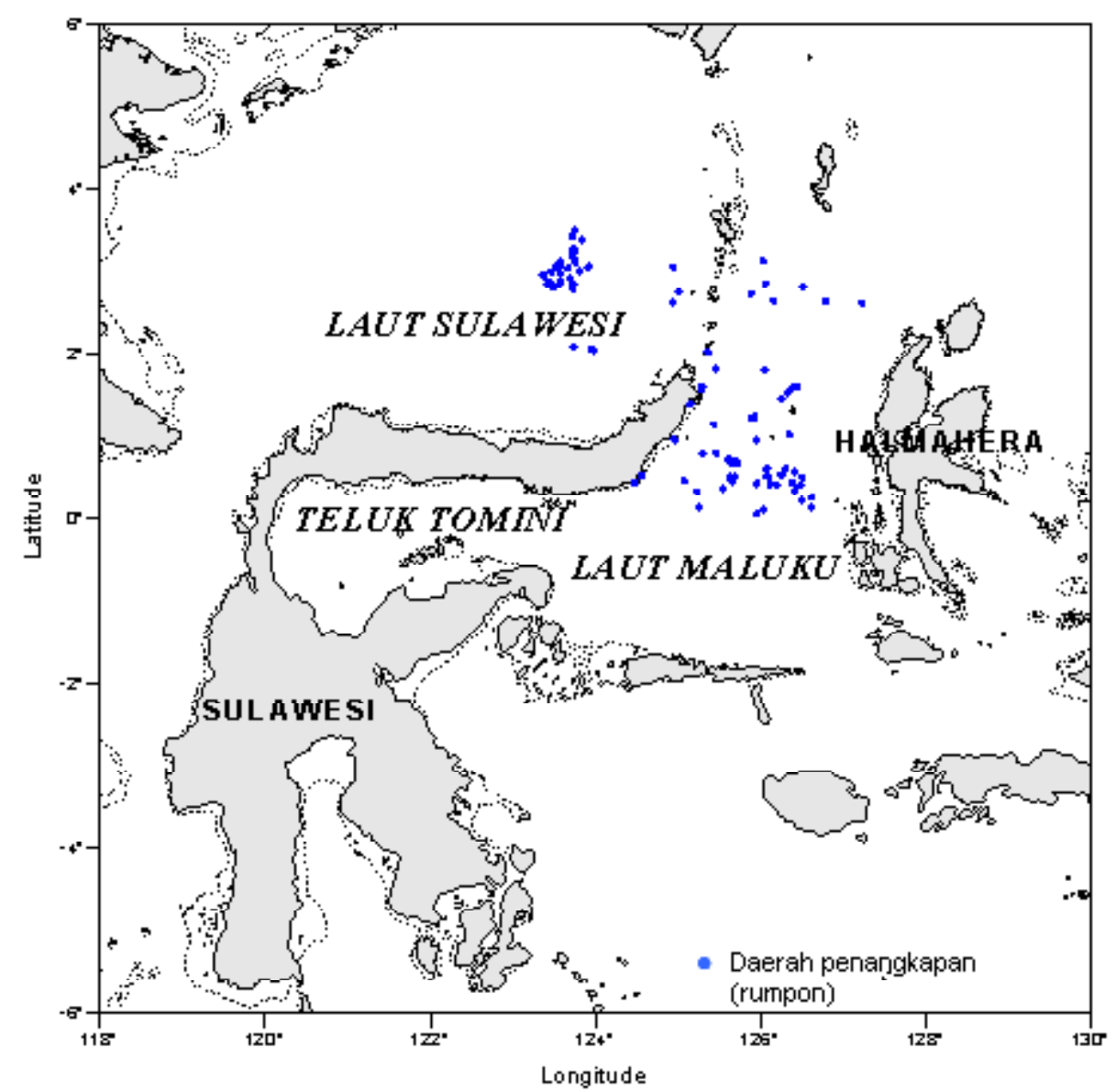

Gambar 2. Daerah penangkapan (rumpon-rumpon) kapal-kapal huhate.

Figure 2. Fishing ground (FADs) of pole and line vessels.

\section{Komposisi Hasil Tangkapan}

Berdasarkan pada hasil observasi yang dilakukan dengan mengikuti kegiatan penangkapan kapal huhate pada bulan Juli 2005 dan Nopember 2005 diperoleh hasil tangkapan cakalang (Katsuwonus pelamis), madidihang (Thunnus albacares), baby tuna (Thunnus spp.), dan tongkol (Auxis spp.) serta hasil tangkapan sampingan yaitu lemadang (Coryphaena hippurus) dan sunglir (Elagatis bipinnulatus). Persentase masing-masing hasil tangkapan dapat dilihat pada Gambar 3 dan 4.

\section{Hasil Tangkapan (Catch), Upaya Penangkapan (Effort), dan Hasil Tangkapan per Satuan Upaya (Catch per Unit of Effort)}

Pada Gambar 5 terlihat trend hasil tangkapan (catch), upaya penangkapan (effort) dan catch per unit of effort baby tuna (Thunnus spp.) dan cakalang (Katsuwonus pelamis) selama periode bulan Juni 2004 sampai dengan Nopember 2005 berfluktuatif. Nilai catch per unit of effort baby tuna (Thunnus spp.) mengalami kenaikan yang sangat signifikan pada bulan Agustus 2004. Hal ini, terjadi karena ada kenaikan jumlah produksi namun jumlah upaya penangkapan sedikit. Pada bulan September 2004 nilai catch per unit of effort kembali menurun karena ada peningkatan jumlah upaya penangkapan yang sangat signifikan sehingga meningkatkan jumlah produksi. Lain hal dengan cakalang (Katsuwonus pelamis) di mana nilai catch per unit of effort cakalang (Katsuwonus pelamis) mengalami kenaikan yang sangat signifikan pada bulan September 2004. Kenaikan catch per unit of effort ini diikuti pula dengan kenaikan jumlah upaya penangkapan dan jumlah produksi. 
Meningkat hasil tangkapan dan upaya penangkapan ini mengindikasikan bahwa pada bulan September (musim peralihan 2) merupakan puncak musim penangkapan baby tuna (Thunnus spp.) dan cakalang (Katsuwonus pelamis), terutama di perairan Laut Sulawesi dan Laut Maluku. Menurut Uktolseja et al., (1991), puncak musim penangkapan cakalang (Katsuwonus pelamis) untuk daerah di kawasan timur
Indonesia pada umumnya terjadi pada musim peralihan 1 (bulan April sampai dengan Juni) sampai dengan awal musim timur. Berdasarkan pada hal tersebut, dapat diindikasikan bahwa telah terjadi perubahan puncak musim penangkapan terutama untuk cakalang (Katsuwonus pelamis) di kawasan timur Indonesia, terutama di perairan Laut Sulawesi dan Laut Maluku.

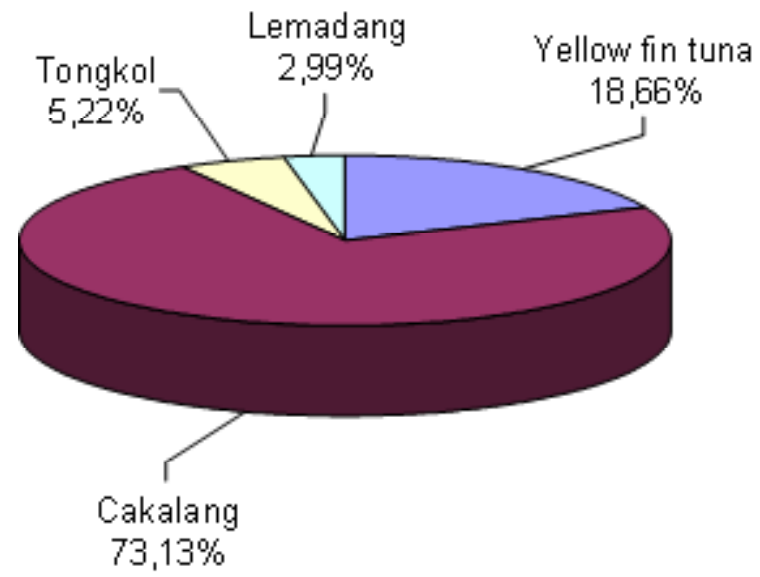

Gambar 3. Komposisi hasil tangkapan kapal huhate pada bulan Juli 2005.

Figure 3. Catch composition of pole and line vessel on July 2005.

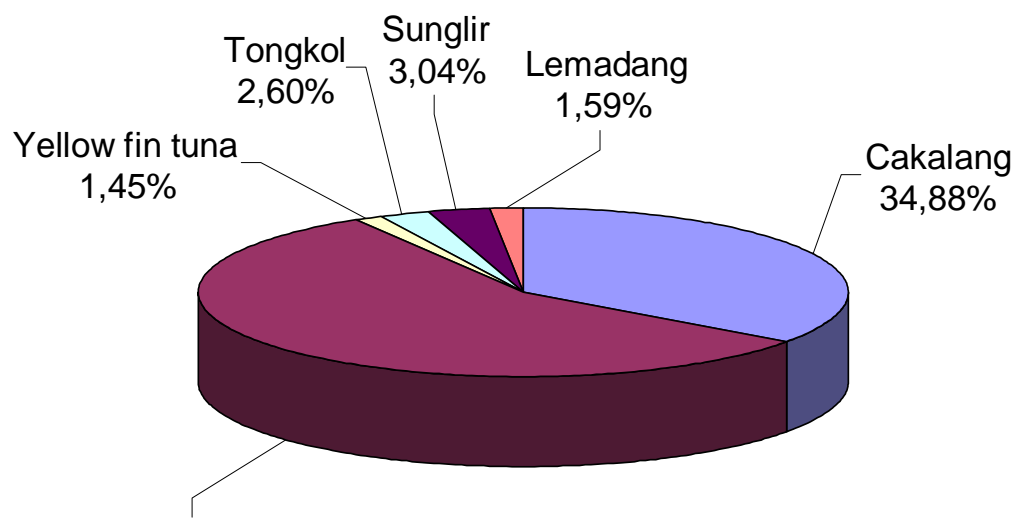

Baby tuna

$56,44 \%$

Gambar 4. Komposisi hasil tangkapan kapal huhate pada bulan Nopember 2005.

Figure 4. Catch composition of pole and line vessel on November 2005.

\section{Ukuran Ikan Pertama Kali Tertangkap (Lc)}

Pendugaan ukuran pertama kali ikan tertangkap digunakan sebagai salah satu pertimbangan dalam pengelolaan sumber daya perikanan. Dapat asumsikan bahwa apabila ikan tertangkap pada ukuran belum sempat matang gonad atau dengan kata lain belum sempat melakukan recruitment, maka sumber daya ikan itu akan cenderung punah. Hal ini, mungkin terjadi karena ikan belum diberikan kesempatan untuk mempunyai keturunan tetapi sudah tertangkap (Balai Riset Perikanan Laut, 2004).
Berdasarkan pada hasil perhitungan diperoleh bahwa ukuran pertama kali tertangkap cakalang oleh huhate 49,3 FLcm (Gambar 6). Menurut Wade (1950) dalam Wild \& Hampton (1994) ukuran pertama kali matang gonad cakalang (Katsuwonus pelamis) (length at first maturity) di perairan Philipina sekitar 40 sampai dengan 40,9 FLcm. Begitu pula hasil penelitian Bunag (1956) dalam Wild \& Hampton (1994) menemukan bahwa ukuran pertama kali matang gonad cakalang (Katsuwonus pelamis) di perairan sekitar pulau-pulau di Philipina 56,7 FLcm. Demikian, cakalang-cakalang (Katsuwonus pelamis) yang tertangkap oleh huhate 
sudah pernah mengalami matang gonad atau pernah melakukan recruitment.

Berdasarkan pada hasil perhitungan diperoleh bahwa ukuran pertama kali tertangkap madidihang ( Thunnus albacares) oleh huhate 51,6 FLcm (Gambar 7). Itano (2000) mengatakan bahwa panjang minimum betina madidihang (Thunnus albacares) pada saat matang gonad, contoh diambil dari ekuator, mempunyai panjang $73 \mathrm{~cm}$. Menurut Collette \& Nauen (1983) ukuran matang gonad madidihang (Thunnus albacares) di perairan Philipina dan Amerika Tengah lebih dari $120 \mathrm{FLcm}$. Demikian, madidihangmadidihang (Thunnus albacares) yang tertangkap oleh huhate belum pernah mengalami matang gonad atau belum pernah melakukan recruitment.

\section{Baby Tuma}
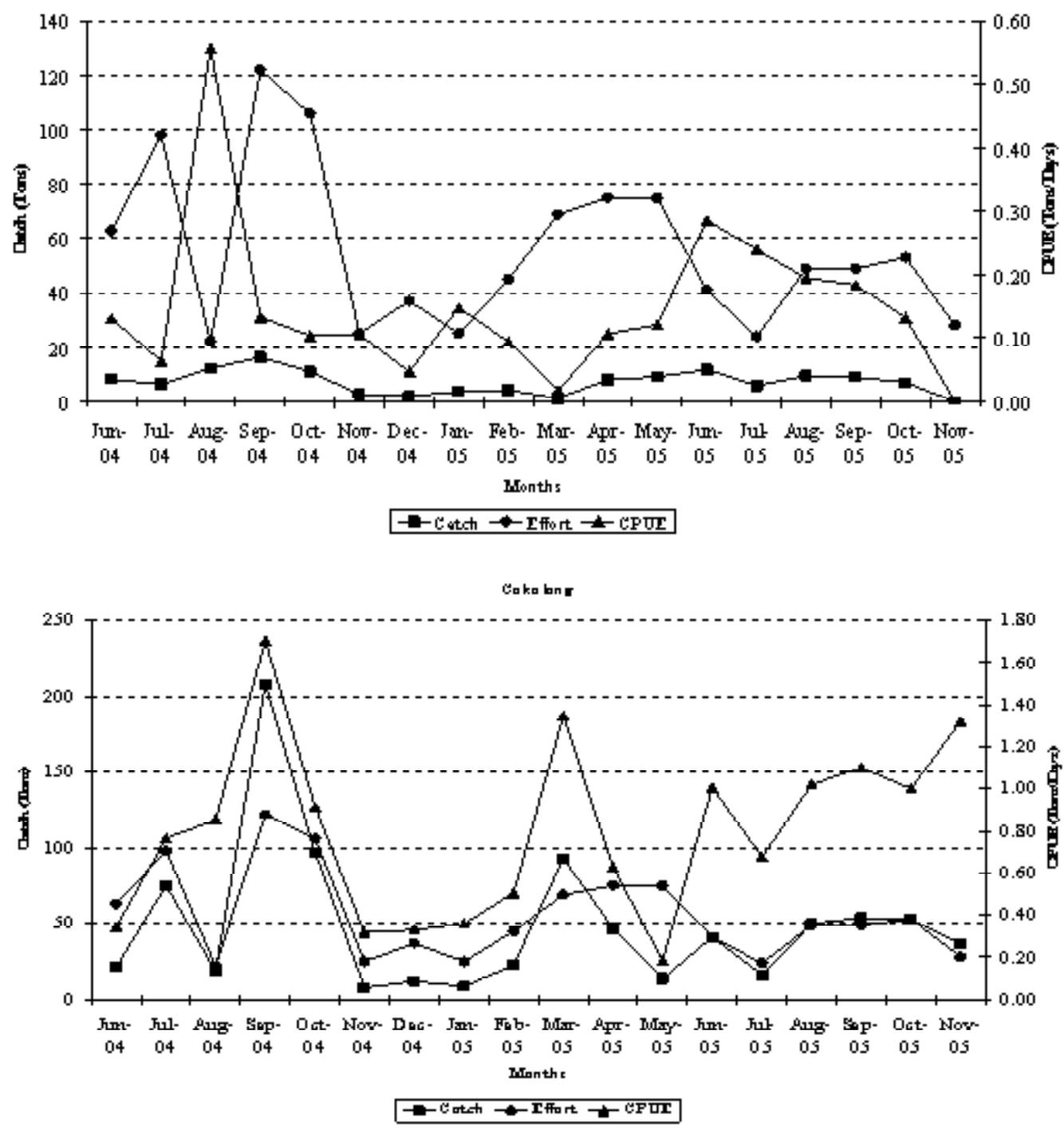

Gambar 5. Fluktuasi hasil tangkapan, upaya penangkapan, dan catch per unit of effort baby tuna (Thunnus spp.) dan cakalang (Katsuwonus pelamis) hasil tangkapan huhate di Bitung dari bulan Juni 2004 sampai dengan Nopember 2005.

Figure 5. Catch, effort, and catch per unit of effort fluctuation of skipjack (Katsuwonus pelamis) and baby tuna (Thunnus spp.) from the catch of pole and line in Bitung from June 2004 to November 2005. 


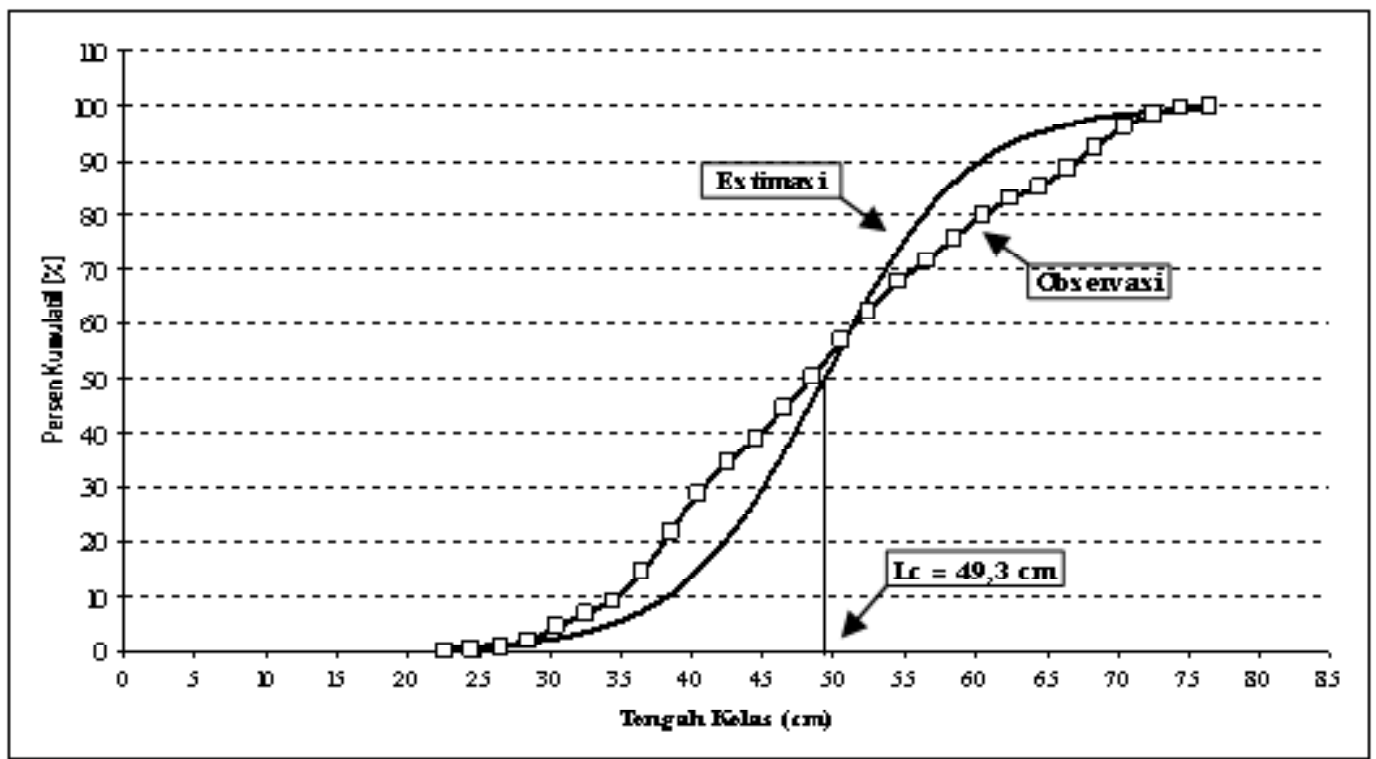

Gambar 6. Ukuran pertama kali tertangkap cakalang (Katsuwonus pelamis) oleh huhate.

Figure 6. Length at first capture of skipjack tuna (Katsuwonus pelamis) caught by pole and line.

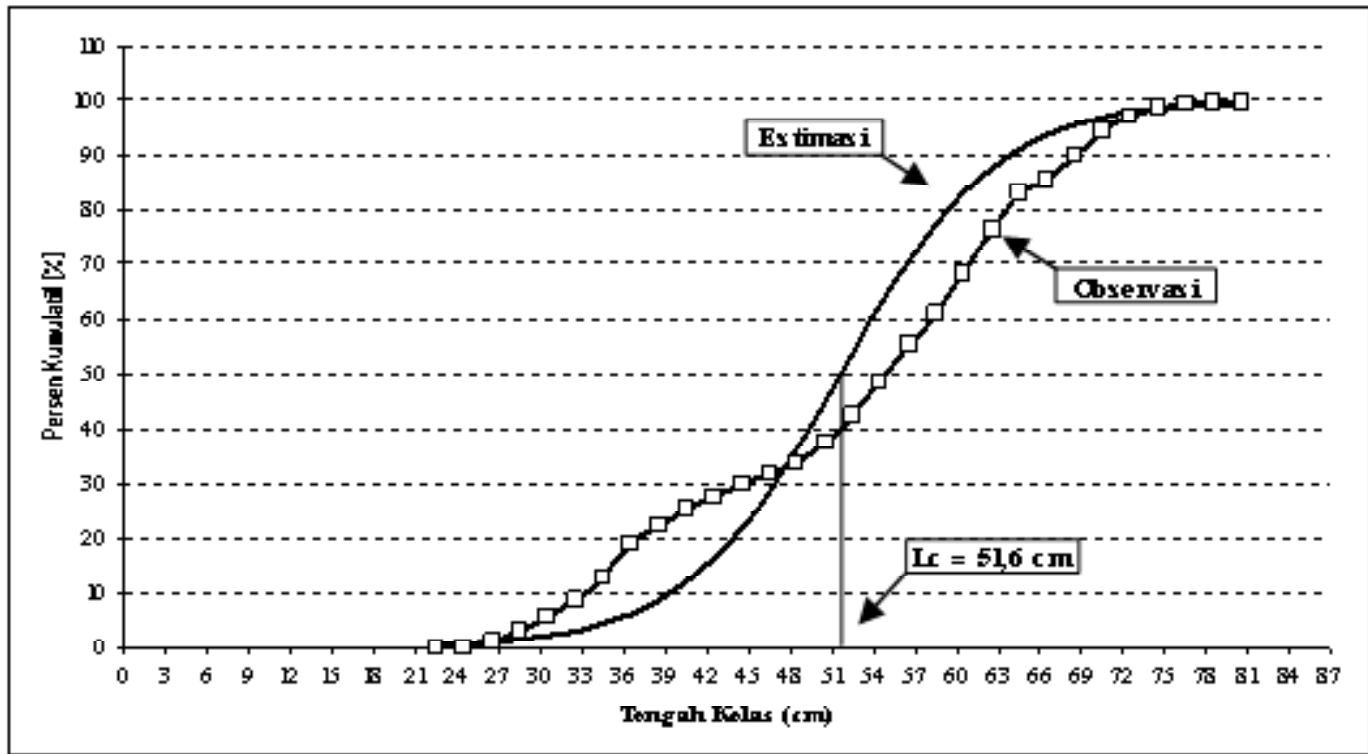

Gambar 7. Ukuran pertama kali tertangkap madidihang (Thunnus albacares) oleh huhate.

Figure 7. Length at first capture of yellow fin tuna (Thunnus albacares) caught by pole and line

\section{KESIMPULAN}

1. Alat tangkap huhate yang terdapat di Bitung terdiri atas joran, tali pancing, dan mata pancing dengan armada penangkapan terbuat dari kayu dan mempunyai gross tonase berkisar 50 sampai denga $80 \mathrm{GT}$.

2. Daerah penangkapan nelayan-nelayan huhate Bitung berupa rumpon yang berada di Laut Sulawesi dan Laut Maluku.
3. Hasil tangkapan huhate Bitung terdiri atas cakalang (Katsuwonus pelamis), madidihang (Thunnus albacares), baby tuna (Thunnus spp.), dan tongkol (Auxis spp.) serta hasil tangkapan sampingan yaitu lemadang (Coryphaena hippurus) dan sunglir (Elagatis bipinnulatus).

4. Nilai catch per unit of effort baby tuna mengalami kenaikan pada bulan Agustus 2004, sedangkan cakalang (Katsuwonus pelamis) mengalami kenaikan pada bulan September 2004. 
5. Ukuran pertama kali tertangkap cakalang (Katsuwonus pelamis) oleh huhate 49,3 FLcm, di mana ukuran ini lebih panjang dibandingkan ukuran pertama kali matang gonad cakalang (Katsuwonus pelamis). Demikian, hasil tangkapan cakalang (Katsuwonus pelamis) yang diperoleh huhate sudah pernah mengalami matang gonad atau pernah melakukan recruitment. Sedangkan ukuran pertama kali tertangkap madidihang (Thunnus albacares) oleh huhate 51,6 FLcm, di mana ukuran ini lebih pendek dibandingkan ukuran pertama kali matang gonad madidihang (Thunnus albacares). Demikian, hasil tangkapan madidihang (Thunnus albacares) yang diperoleh huhate belum pernah mengalami matang gonad atau belum pernah melakukan recruitment.

\section{PERSANTUNAN}

Kegiatan dari hasil riset kelimpahan sumber daya ikan pelagis besar di Laut Halmahera dan Laut Sulawesi, T.A. 2005, di Balai Riset Perikanan LautMuara Baru, Jakarta.

\section{DAFTAR PUSTAKA}

Balai Riset Perikanan Laut. 2004. Status stok, dampak penangkapan, dan bioekologi sumber daya ikan pelagis kecil dan demersal di perairan Selat Malaka. Laporan Akhir Penelitian. Balai Riset Perikanan Laut. Pusat Riset Perikanan Tangkap. Badan Riset Kelautan dan Perikanan. Departemen Kelautan dan Perikanan. Jakarta.

Collette, B. B. \& C. E. Nauen. 1983. FAO Species catalogue. Vol.2. Scombrids of the World. An Annotated and Illustrated Catalogue of Tunas, Mackerels, Bonitos, and Related Species Known to Date. FAO Fisheries Synopsis. (125) Vol.2. FAO. Rome. 137 p.

Dinas Perikanan dan Kelautan Propinsi Sulawesi Utara. 2004. Buku Tahunan Statistik Perikanan Tangkap Propinsi Sulawesi Utara Tahun 2003.

Diniah, M. A. Yahya, S. Pujiyati, Parwinia, S. Effendy, M. Hatta, M. Sabri, Rusyadi, \& A. Farhan. 2001.
Pemanfaatan sumber daya tuna (Thunnus) dan cakalang (Katsuwonus pelamis) secara terpadu. Makalah Falsafah Sains. Program Pasca Sarjana Institut Pertanian Bogor. Bogor.

Itano, D. G. 2000. The reproductively biology of yellow fin tuna (Thunnus albacares) in Hawaiian waters and the western tropical Pacific Ocean: Project Summary. SOEST 00-01. JIMAR Contribution 00328. University of Hawaii. $69 \mathrm{p}$.

Kerstan, M. 1985. Age, growth, maturity, and mortality estimates of horse mackerel (Trachurus trachurus) from the waters West of Great Britain and Ireland in 1984. Arch. FischWiss. 36 (1/2). 115-154.

Sparre \& Venema. 1999. Introduction to tropical fish stock assessment. Part 1. Manual. FAO Fisheries Technical Paper No.306/1. Rev. 2. 438 p.

Stequert, B. \& B. Ramcharrun. 1996. Reproduction of skipjack Tuna (Katsuwonus pelamis) from the western Indian Ocean. Aquatic Living Resources. 9. 235-247.

Subani, W. \& H. R. Barus. 1988. Alat penangkapan ikan dan udang laut di Indonesia. Jurnal Penelitian Perikanan Laut. Edisi Khusus. No.50 Tahun 1988/ 1989. Balai Penelitian Perikanan Laut. Badan Penelitian dan Pengembangan Pertanian. Departemen Pertanian. Jakarta. 248 hal.

Uktolseja, J. C. B., B. Gafa, S. Bahar, \& E. Mulyadi. 1991. Potensi dan penyebaran sumber daya ikan tuna dan cakalang (Katsuwonus pelamis). Dalam: potensi dan penyebaran sumber daya ikan laut di perairan Indonesia. Direktorat Jenderal Perikanan. Pusat Penelitian dan Pengembangan Perikanan. Pusat Penelitian dan Pengembangan Oseanologi. Lembaga Ilmu Pengetahuan Indonesia. Jakarta. Hal.29-43.

Wild, A. \& J. Hampton. 1994. A Review of the biology and fisheries for skipjack tuna, Katsuwonus pelamis, in the Pacific Ocean. In Interactions of Pacific tuna Fisheries, R. S. Shomura, J. Majkowski, \& S. Langi, eds. FAO Fish. Tech. Pap. 336/2.1-51. 